\title{
THE EFFECTIVENESS OF SIMPLIFIED COMPUTER-BASED TEST (CBT) SYSTEM AS A SUBSTITUTE FOR PAPER-BASED TEST (PBT) SYSTEM
}

\author{
RadenAchmadDzulfikarHermawan ${ }^{[1]}$, \\ SyifaNafiah ${ }^{[2]}$, NabiilaYumnaGhina ${ }^{[3]}$, \\ Ni LuhDeaPradnyani ${ }^{[4]}$ \\ Zenius Education, \\ Gedung Gajah Unit ABC Lantai 5 B3, \\ Jl. Dr. Saharjo Raya No. 111, JakartaSelatan, Jakarta,Indonesia
}

Email: [1] zulfikar.hermawan@zeniuseducation.com, [2] syifa.nafiah@zeniuseducation.com,

[3] nabiila.ghina@zeniuseducation.com, [4] niluhdea@zeniuseducation.com

\begin{abstract}
:
Almost 70\% National Exam process in all school levels in Indonesia is using computer-based test (CBT). However, the preparation is still hardly followed by teachers because of incomplete understandings of CBT usage applied in daily teaching. We attempted a solution by creating simplified CBT that is hopefully eases teacher in administering quizzes or exams along with reducing teacher workloads in preparing PBT, completed with questions bank. Our CBT aims to: 1) Measure the effectiveness of CBT as PBT substitute. 2) Seeking particular features that are most helpful for teachers in understanding CBT usage. Pilot implementation has been done in SMPN 1, Semarang, Central Java, and SMANBARA, Singaraja, Bali. The implementation includes installation, comprehensive training for teachers and administrators, and continuous monitoring. After one month period, we underwent an in-depth interview for selected teachers and stakeholders and deployed questionnaires regarding CBT usage measurement. The result is these two pilot schools have used CBT continuously for converting most of the quizzes, daily exams, and national exam tries out from PBT into CBT. It indicates that CBT is capable of fulfilling the needs of teachers in reducing teaching workload. Favorable CBT features were editable questions bank; simultaneous questions (in images) upload; automated scoring and questions item analysis. This concludes that our teachers are willing to apply CBT system in their daily routines, if they are given the right tools, training, also monitoring/coaching.
\end{abstract}

Keywords: Computer-Based Test, Paper-Based Test, E-Learning Systems, Teachers Technology Adoption. 


\section{INTRODUCTION}

\section{Background}

The education system in Indonesia requires each level of schools needs to evaluate to know the extent of the learning objective is attained. One evaluation forms conducted by Indonesian government is the national examination for students at the final year of middle and high schools. Indonesian national exam is a standardized evaluation system of primary and secondary education and the equation of quality of education levels among the areas that are conducted by the Center for Educational Assessment, The Department of Education. To improve the education system, Indonesian government, The Department of Education always upgrades its education system by changing of regulation on National Exam from PBT system to the CBT system.

The national examination of Computer-Based Test is a computer-based test whose item selection and presentation are administered in a computerized manner in which the test takers are given a different package of test items each ${ }^{2}$. In this test, students are no longer use a paper-based system, but rather, they use entirely a computer-based system already programmed to make the execution of the test more useful. Indonesia began to administer the Computer-Based National Exam (UNBK) in 2015. At 2014/2015, there were only 500 schools $(0,8 \%)$ who participated on UNBK. In the $2015 / 2016$, the participated schools on UNBK increased to 4.400 schools $(7,1 \%)$ and sharply increased to 28.380 schools $(45,5 \%)$ in 2016/2017. And in 2017/2018, participated schools on UNBK increased to 59.467 schools $(92,2 \%)$ (Kemendikbud,2018).

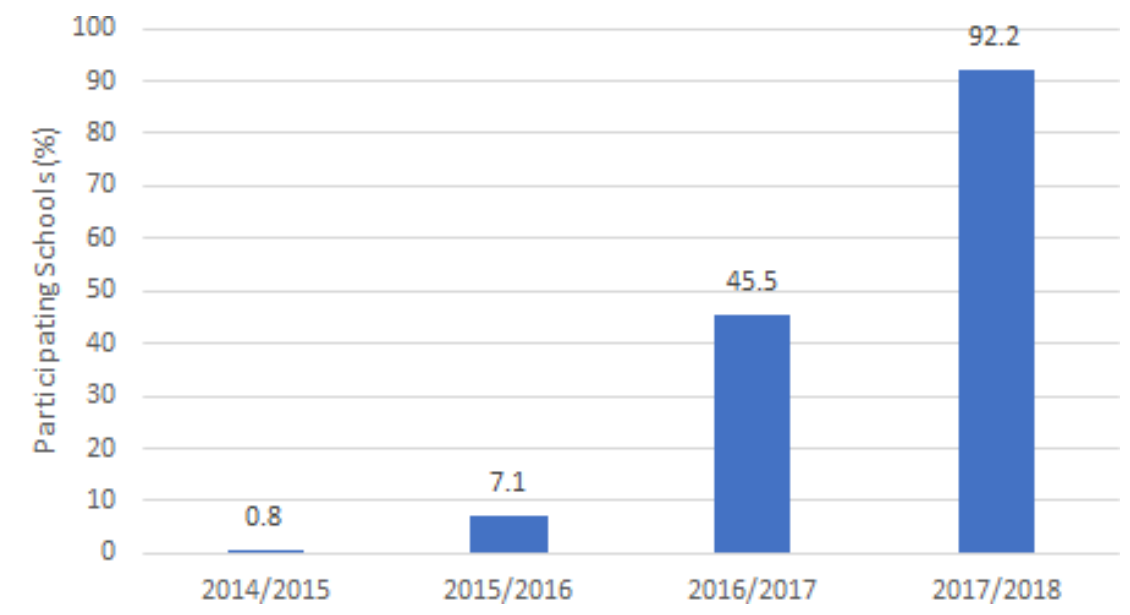

Figure 1. Number of Schools Participating in Computer-Based National Exam (Kemendikbud, 2018)

Although there is an increasing number of schools participating in UNBK, the implementation of the UNBK still faces various problems. The lack of technological literacyin 
Indonesian teachers is a crucial issue in implementing the UNBK system. There are still many Indonesian teachers who have not been technologically literate, so the adoption process of the CBT system in schools becoming increasingly difficult and prefer to using the PBT system. Syukur, Imam A (2014) stated that the lack of technological literacy levels in teachers occurred due to a lack of ICT mastering, inadequate facilities and infrastructure, and the lack of ICT training forteachers.

The adoption process of CBT system is an important thing to be applied in school because this process aims to prepare teachers and students to face UNBK. Moreover, the CBT system is considered more effective and efficient compared to the PBT system. Using CBT system in schools has many advantages such as more budget savings through reducing budgets for printing exams, quick test results, but also minimizing cheating during exams through the randomizing system so that each student will get a different sequence of questions. Furthermore, we hope CBT adoption will triggering the adoption of other educational technologies.

In this research, we will examine the process of adopting technology in the education system by teachers and schools through the CBT system and also finding the key reason for teachers and schools who have successfully adopted new technologies in their learning systems which are then applied more broadly.

\section{Research Objectives}

Along with the implementation of a new technology adoption process, we want to measure the effectiveness of CBT as PBT substitute, seeking particular features that are most helpful for teachers from using CBT system, determining reasons why schools stakeholders and teachers want to adopt CBT system, and searching for fittest adoption methods for teachers toward technology.

\section{Hypothesis}

The hypothesis we have in this research is that the CBT system can make the learning system more efficient and save costs, energy, and time. And also schools stakeholders and teachers will be interested in adopting new technologies if this technology is proven to help them reduce their workloads. This can work effectively if the schools is given comprehensive training. 


\section{LITERATURE REVIEW}

\section{Comparison Between Technologically Enhanced Learning and Traditional Learning}

Furió et al. (2014) conducted research to compare learning effectiveness and satisfaction between traditional learning method compared to technologically enhanced learning method. This study used water cycle as learning material. It was conducted with 38 elementary school students as samples, age 8-10 years old. Technology-based learning method conducted by using a game that could be accessed through a smartphone as the media.

The research showed that students who received traditional learning method and technology-enhanced learning method were equally increased significantly in the mastery of learning material. According to statistical analysis, there was no significant difference between the two group's mastery. A compelling difference appeared from their learning satisfaction. The technology-enhanced group statistically showed higher learning satisfaction than the group who had the traditional learning method (Furió et al.2014).

Learning efficacy comparison between traditional learning, pure e-learning, and blended learning already observed by Al-Qahtani and Higgins (2013), in this research they used 148 students of Islamic Culture course (101) at Umm Al-Qura University in Saudi Arabia. The student randomly assigned into three different group: traditional learning (classic face to face learning), pure e-learning (no physical interaction between class participant), and blended learning (combination between traditional learning and e-learning). The study concludes that there is a statistically significant difference in final test result between the blended learning group and rest of two groups, with the blended learning have significantly higher test result. From this study, we can conclude that the combination between e- learning and traditional face to face learning is the bestoption.

\section{Factors Affecting Teachers Adoption of Digital Technology}

Tondeuret al. (2016) conducted researched about keys factor in teacher technology adoptions. This research used 688 pre-service teachers in Flanders, Belgium as their samples. This research concludes that technology integration needs to be applied as a systematic process throughout the entire teacher training program. Several strategies in teachers training program that proved to be vital in technology adoption when they served as teachers, these factors are:

1. Using teacher trainer as a role model in technologyadoption

2. They are given deep understanding of the role of ICT ineducation

3. They trained to use technology from the beginning of theirtraining 
4. They got continuous feedback in usingtechnology

These strategies count heavily on teacher trainer as role models, and the problem is there are insufficient technology-using teacher educators who can inspire pre-service teachers to use technology. Gokstaset al. (2009) pointed out that teacher trainer often lacks the knowledge, skills to teach technology adoption to pre-service teachers. As stated above, the involvement of teacher educators in teacher design teams may constitute an effective strategy to develop competencies necessary to integrate digital resources into teaching and to structure the professionalization of teachereducators.

Comparison Between the Computer-Based Test (CBT) and Paper-Based Test (PBT), In Term of Student Performance and Acceptance Level

In most the studies, there are no significant differences in students performance between the group that took computer-based and the group that took paper-based test. For example, a study conducted by wang et al. (2008) gave a result that there are no statistically significant differences in K-12 student reading achievement scores. This latter confirmed by Boevéet al. (2018) which evaluate student performance in different exam modes in a Biopsychology course, in the psychology program. The course has 401 participants who will be divided into two different exam mode, CBT and PBT. The result is there is no statistically significant performance difference between two type of test. However, Boevéet al. (2018) found that $50 \%$ of the student prefer PBT, $28 \%$ of the student prefer CBT, and the rest said to have no preference. This show us, although CBT and PBT have no impact on student performance, PBT is potentially still more favorable for students. this is caused by students not yet familiar with computer-based tests. Another possible explanation is students taking computer-based exams were unrest from possible technical problems that might appear. Therefore institutions that want to conduct exam using CBT need to invest in good CBT applications and supporting facilities. This includes investing in adding more test-taking functionalities so that students test-taking experience may be as optimal as possible (Boevéet al.,2018).

Implementation of Technology in the Education System by Teachers

Syukur (2014) conducted researched about the implementation technology by using laptops and internet in the teaching-learning process. This research used 309 elementary to high schools teachers in Nganjuk Residence, East Java, as his samples. The factors that influence the interest in implementing technology to the teaching-learning system by the teacher are:

1. The demands from the school or government to have the ability ofICT. 
2. Awareness to create a teaching-learning system more interesting, effective, and efficient.

This research found that teachers in Nganjuk still rarely use technology such as laptops and internet in the teaching-learning process. The majority of those who have never and rarely use the internet for teaching-learning process are teachers in the age group $>45$ years, while those who use the internet most often for teaching-learning process are teachers aged 35-45 years with the majority of vocational schoolteachers.

The low level of technology implementation in the teaching-learning system occurs because of the low ability of teachers in mastering ICT, inadequate facilities and infrastructure, and the lack of ICT training forteachers.

\section{National Examination in Indonesian Schools}

The national examination in Indonesia is conducted to evaluate the performance of students in their final year in junior and senior high school. To make this national examination more effective, the Indonesian government developed a new system, the national Examination Computer-Based Test (UNBK). Retnawatiet al. (2017) conducted researched about Indonesian national examination Computer-Based Test (UNBK). This study found several factors that could help the implementation of UNBK runs well, namely:

1. Adequate facilities at the school.

2. School geographical location of theschool.

3. Human resources that are capable and qualified inIT.

4. Preparing teachers and students to face UNBK by conducting UNBK try out with CBT systems and UNBK training for teachers andstudents.

The Indonesian Ministry of Education and Culture states that in the 2019 national examination requires all schools to implement UNBK. So schools, including teachers and students should prepare to face UNBK. In the preparation and implementation of UNBK, teachers must have initiatives to learn new technology. Also, the government must also facilitate distribution of UNBK facilities in Indonesian schools. And the schools can conduct UNBK try out using the CBT system so the students will get familiar with the CBT system (Retnawatiet al., 2017). 


\section{METHODOLOGY}

\section{Research Outline and Timeline}

This research was conducted in two schools; one is Bali Mandara Senior High School (SMANBARA), Bali and the other is SMPN 1, Semarang, Central Java. The research is conducted alongside our pilot implementation of Computer Based Test (CBT) product. Below is our research timeline:

Table 1. Research Timeline

\begin{tabular}{|l|l|l|}
\hline No & Agenda & Conductment \\
\hline 1 & Determining pilot schools & August \\
\hline 2 & Training, Workshop, and Tryout Simulation & August \\
\hline 3 & Independent Usage & Started at September \\
\hline 4 & Evaluation & November \\
\hline
\end{tabular}

\section{Determining Pilot Schools}

Overall, the pilot schools determination were based on schools whose principals are open to new technology and encouraging the teachers to be technology-savvy. Relationship with those schools are built through our partners which we approached independently to finally had an agreement together for the pilot implementation of our product. The additional value of SMANBARA in Bali was that its school already had complete facilities and infrastructure, mainly internet network. This made the implementation run easy. Meanwhile, SMPN 1 in Semarang had standard public school technology, whose internet and network access was only within the library and computer laboratory.

\section{Training, Workshop, and Simulation}

After implementation, we conducted training, workshop, and simulation in each school. Training and workshop were done simultaneously since training was when we presented how to use our CBT. The workshop was done right away after the training. During the workshop, the teachers tried our CBT by themselves and applied what we presented before, with our assistance. Our training for the teacher was usually simplified and completed with presentation slide, video, and written tutorial guide. Besides training for teachers, we also did training for teachers whose technology competency were high and school admin, to train the more sophisticated features in the hope that they would teach the other teachers in their schools.

The simulation was done with objectives that teachers independently could try our products through tryouts. This was also done to ensure them that the usage of CBT is easy to 
use and ease their workloads. During simulation, they made their own problem sets, asked the students to do the tryouts, then directly saw the tryouts result and their question-item analysis, which are two main features that were expected to reduce their workloads. We made sure that during simulation, all teachers could operate the CBTsmoothly.

\section{Independent Usage and Monitoring}

After ensuring that the teachers were independently capable, we let both schools use the CBT independently. The teachers were encouraged to use the CBT in their quizzes, daily exams, midterm tests, and finals. During this, we offered our assistance and did monitoring remotely and directly through visit inspection. The assistance and monitoring were done with objectives to 1) helping schools if there were any difficulties or application error during the use, 2) monitoring CBT use by schools, ensuring that they use it in their daily activities.

\section{Evaluation}

The evaluation aimed to see how the implementation was going after one month use by each school. The key indicators of success CBT implementation are 1) Exam practice can be economical (reducing cost); 2) Ease teacher's workload on administrative tasks; 3) Teachers experience CBT simple use; 4) Teachers are willing to use CBT in the future regularly. Those indicators are checked through two evaluation methods; quantitative and qualitative. We obtained quantitative evaluations from teachers by questionnaire and qualitative evaluations from schools stakeholders through in-depthinterview.

For quantitative evaluation, we sent feedback questionnaire to 21 teachers in SMANBARA, and 20 teachers in SMPN 1, Semarang, those are all of the teachers who have used our CBT application. Items evaluated through questionnaires include:

1. CBT application usage in their daily activity as ateacher?

2. Does the CBT application help facilitate their dailywork?

3. Does the CBT application help facilitate the process of carrying out theexam?

4. Do they want to use the CBT application continuously in thefuture?

For qualitative evaluation, we conduct an in-depth interview to school's stakeholders. We conduct a deep interview to cover things that are difficult to obtain via questionnaires suchas:

1. Whether the use of the CBT can reduce examcost?

2. What makes them interested in moving from PBT toCBT?

The results from the quantitative evaluation will be further analyzed whether it's answering the questions and indicators that we proposed. Alongside, the result of qualitative evaluation would be analyzed to support the quantitative data. Thus, we would be getting trusted evaluation data that could conclude the objectives of this research. 


\section{RESULT AND DISCUSSION}

Based on our evaluation, we arranged the discussion into four points: School Information, Comparison of Exams Using PBT and CBT, Deep Interview Results, Quantitative Evaluation Analysis, and Favorable Key Features in CBT.

\section{School Information}

Correspondents were teachers from two different schools which some of them were already technology savvy. Each school's principals were also interested in technologyenhanced learning and very open to new technologies. We gained some information during visits and school's stakeholders deep-interview about each school's story in general and their openness to technology.

The principal of Bali Mandara Senior High School (SMANBARA), Drs. I NyomanDarta, MPd. was very well known in Bali as a principal who adapts to newest updates within the education world, mainly in the technology sector. SMANBARA was known as a public school in Bali who specifically accepted children from low-income families. The school has a dormitory system, where students sleep and do daily activities within the school environment.

As a reference school in Bali Province, SMANBARA had done UNBK since 2016. Most of the teachers are younger than 35 years old; thus, they are very open to trying new technology which able to increase their work effectiveness. SMANBARA has two computer laboratories, where each lab consisted of 40 computers. Besides, every student in SMANBARA has a laptop. Hence, it is a very technology-adapted school. This school also adapted credits system (SKS) in its learning, resulting more flexible time for students.

The principal of another school, 1 Public Junior High School Semarang (SMPN 1) had the same thoughts and similar vision about her way of leading. Mrs. NiningSulistyaningsih was welcoming every new technology came at her schools. She thought that either senior or junior teachers must be equally encouraged to be technically capable.

As the school was one of the top three schools in Semarang City, it had outstanding achievements throughout the years. The principal also consistently did innovations for improving student's learning through any possible ways. One of its innovation was the launch of "MeroketBersama". "MeroketBersama" was a project initiated by the school's alumni who offered learning assistance for overcoming UNBK every weekend for students. Performing UNBK since 2015, the school did very well since the school has four computer laboratories, enough electrical power and established internet network. 
Quantitative evaluation analysis showed that the total correspondents are 39 teachers and two vice principals, which 21 respondents are from SMANBARA and 20 respondents from SMPN 1. The ratio of male and female teachers is 65\%:35\%. Teachers are coming from various subjects, $65 \%$ of them are teachers whose subjects are being tested in the National Exam, and the rest $35 \%$ arenot.

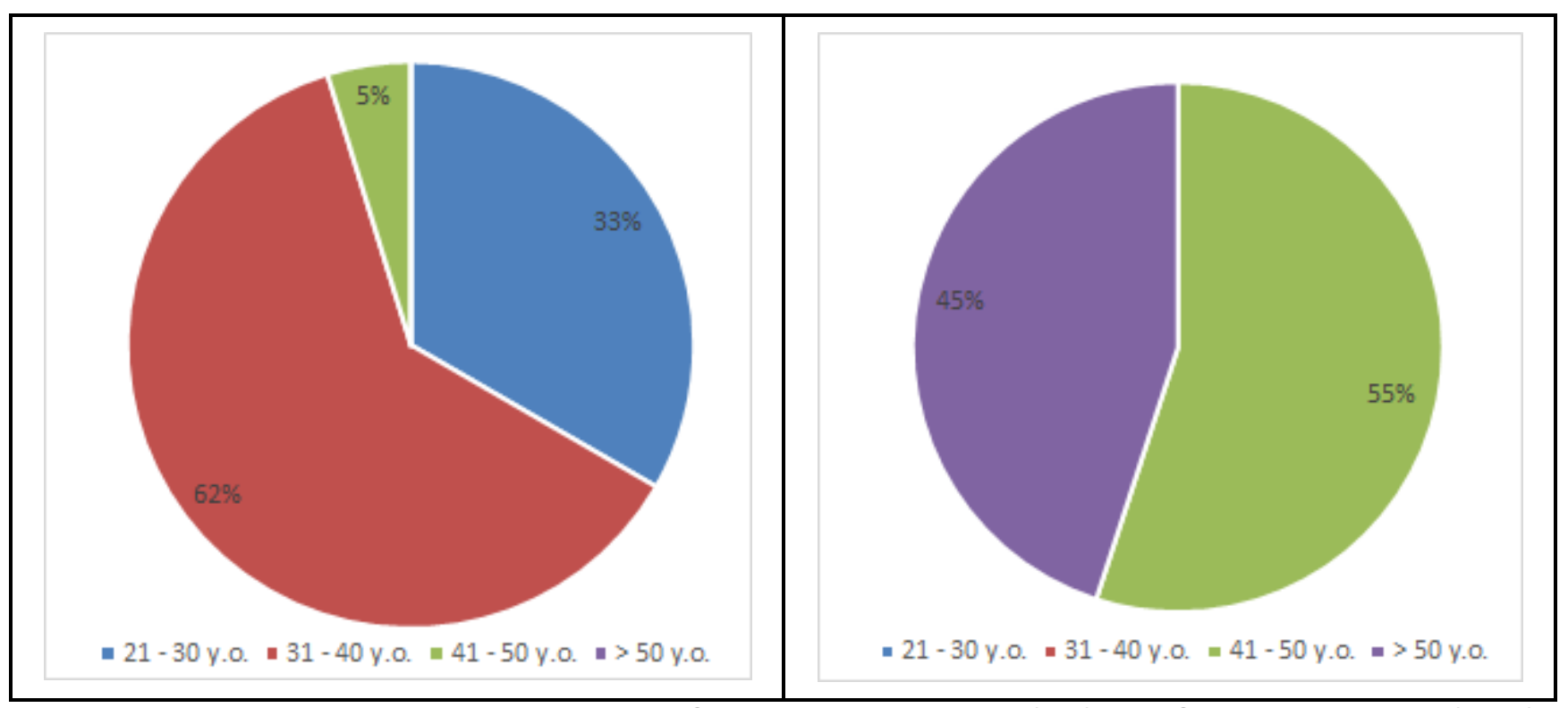

Figure 2. Age distribution of SMANBARA teachers (left) and SMPN 1 teachers (right)

We divided the age range to $21-30$ years old; $31-40$ y.0.; $41-50$ y.0.; and $>50$ y.o. Both schools show a very extreme age range of teachers. In SMANBARA, 95\% of its teachers are young, with 33\% between 21-30 years old and 62\% between 31-40 years old (Figure 1). Meanwhile, SMPN 1 shows the extreme. There are no young teachers at SMPN 1, as 55\% of the teachers are between $41-50$ years old, and $45 \%$ of them are more than 50 years old. Here, we can conclude that teachers at SMANBARA are young and teachers at SMPN 1 are old. 


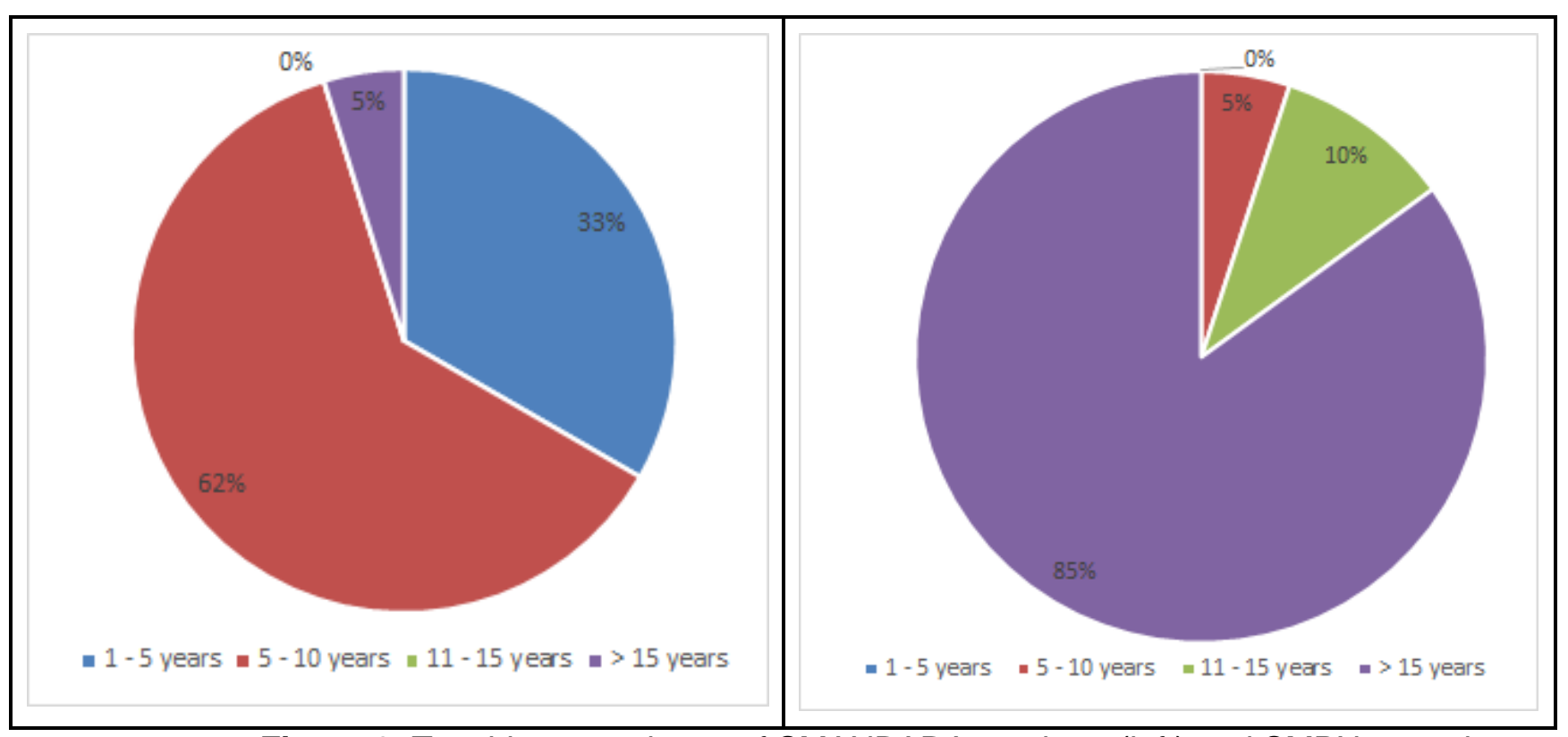

Figure 3. Teaching experience of SMANBARA teachers (left) and SMPN 1 teachers

(right)

However, despite their age, teachers in SMANBARA have sufficient experience in teaching. Many teachers (62\%) are having experience for 5-10 years. The second most are teachers with experience 1-5 years (33\%). Both schools show extreme results again because SMPN 1 shows that 85\% of their teachers have teaching experience of more than 15 years. Only $10 \%$ have teaching experience of $11-15$ years, and the rest is $5-10$ years. There are no teachers who have teaching experience in less than five years. The conclusion is teachers in SMPN 1 are having more years of teaching experience than teachers in SMANBARA.

\section{Comparison of Exams Using PBT and CBT}

Based on our observations to both schools, we concluded that there are two ways of conducting exam, they are Paper Based Test (PBT) and Computer Based Test (CBT). Below are the flows of how the two exams are done (both schools are having the same way of doing the exams):

\section{Paper Based Test (PBT)}

In the paper-based test, the teachers are having to prepare a lot of things beforehand and doing a lot of things too, afterward. This can be shown from the flow above at Table 1 , the yellow column. Before the exam, teachers have to organize problem sets which they conduct through browsing or recreating from existed problems in thebooks. 


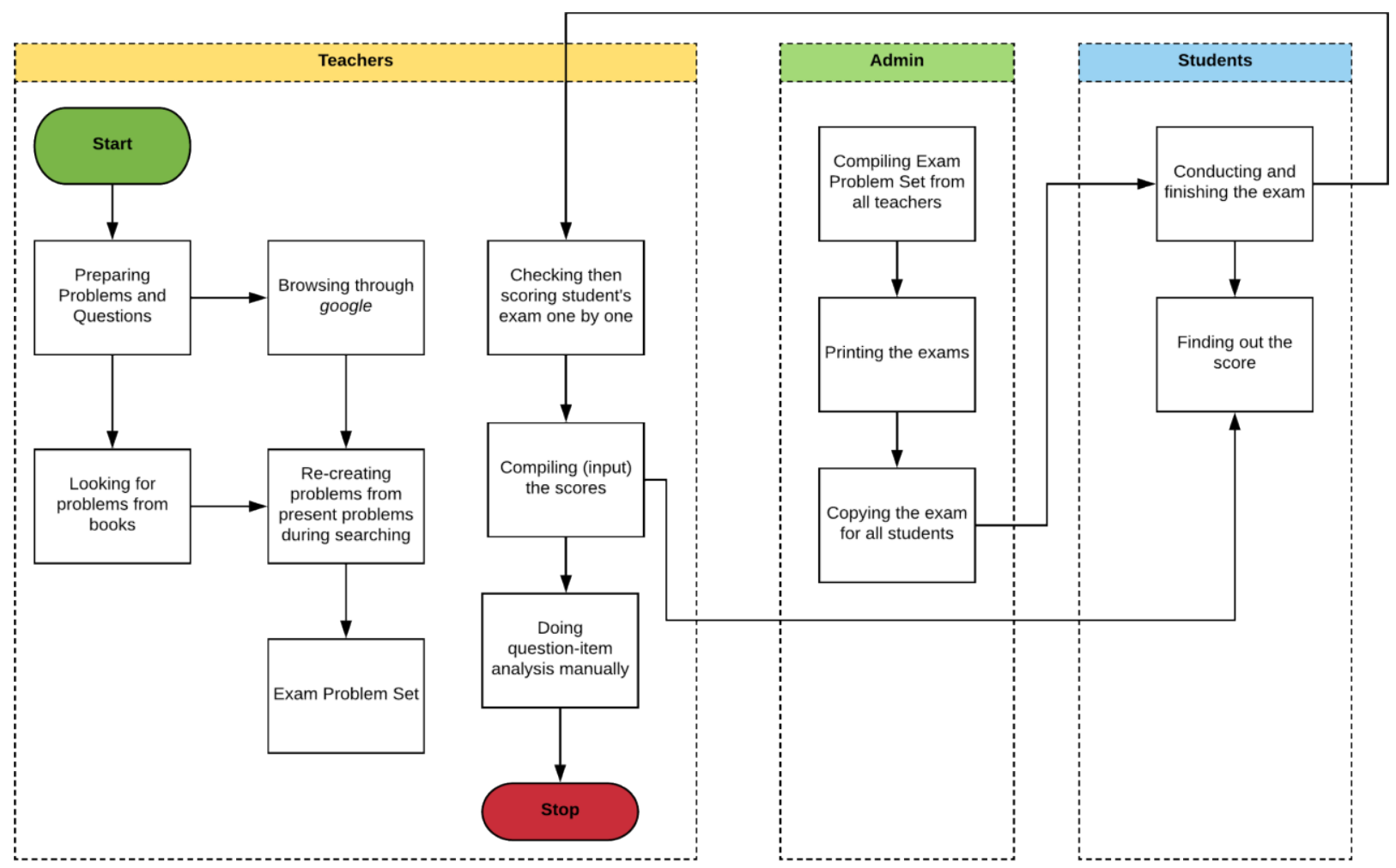

Figure 4.PBT exam system in school

Later on, the clerk jobs are started by admin. Admin has to compile all problem sets that teachers made, then printing it for the original copies. Then, the students are given the problem sets that have been copied. Remember that the total number of students can exceed almost more than 900. It requires a lot of tools, money for buying the tools, the admin also should sacrifice his/her time and make so much effort.

From here, the problem sets are finally ready to be given to the students. Students could start doing the exam, but in here teachers also have to be the supervisors during the exam so there won't be any fraud practice. This adds the teacher's workload.

After the exams are finally completed, now it's time for teachers to check all of the student's answers manually. Teachers have to check one by one per student to check their answers. Sometimes, because of too many exams they need to check, scoring mistaken can happen which results in additional work later on; changing the student's scores, they have input.

When each student has already had his/ her exam score, teachers have to compile the scores manually into their laptops. After ensuring that all of the scores are already submitted, 
teachers have to do question-item analysis which is essential for their reports. This is done manually by entering the formulas for each variable, using Microsoft Excel. After performing all those administrative steps, teachers finally able to announce the students'score.

\section{Computer Based Test}

Based on our observation, using our computer-based-test is assumed to make teachers easier when conducting an exam. Above is the flow of teachers when using our CBT for exams (Figure 5) which looks simpler than PBT (Figure 4). By using CBT, the admin has only one job, to upload data students and teachers.

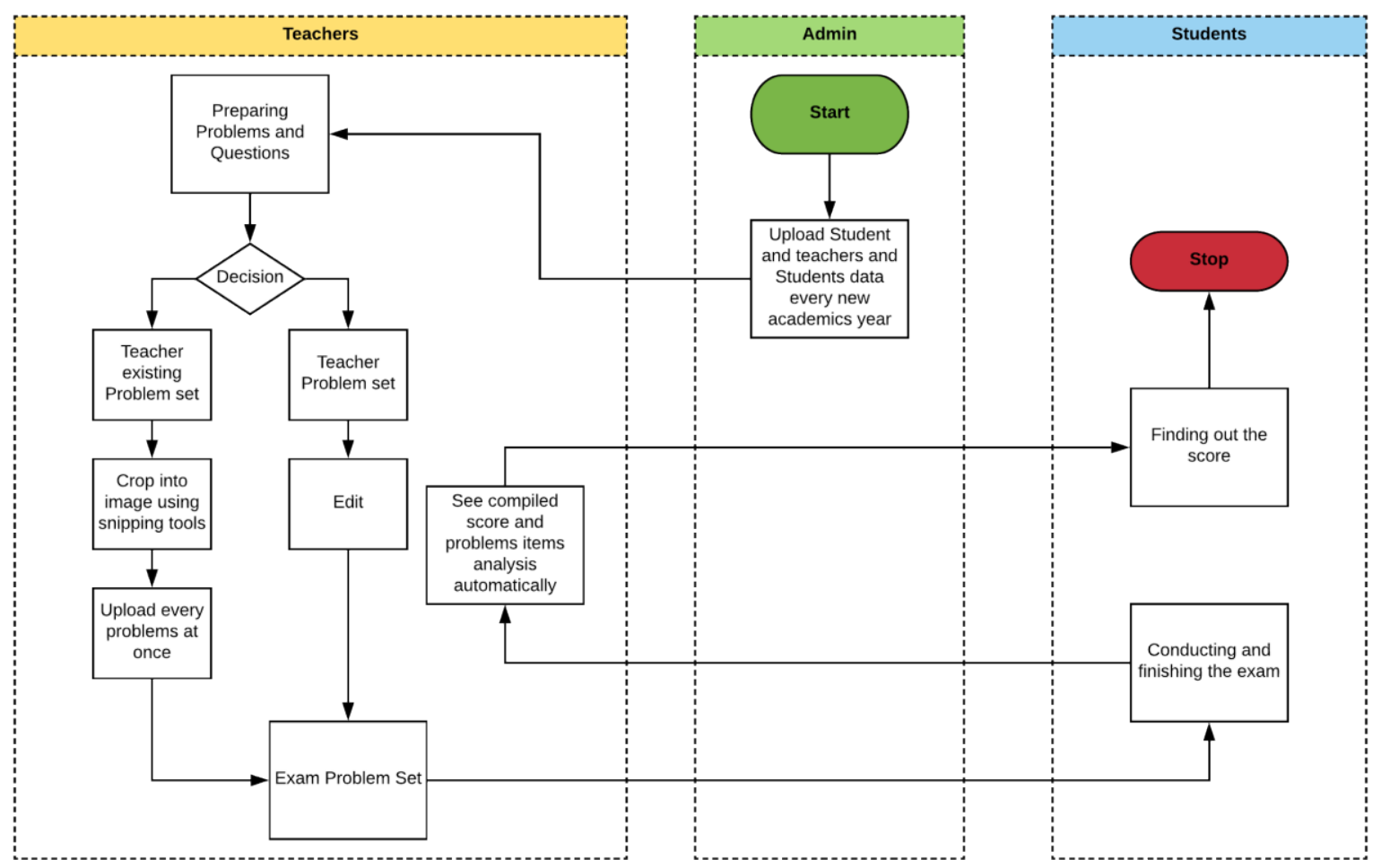

Figure 5.CBT exam system in school

When preparing problems and questions, the teacher could directly make it using our CBT. The teacher could use their existing problem sets. Usually, they made it in a file of word or PDF. Afterward, the teacher could easily crop their problem sets into images form (extension .jpg or .png). Therefore, they could upload the images at once into to make one problem set.

Besides cropping the problems from a file, the teacher could also make a new problem set with our CBT. Inside our CBT, there is also a feature of questions bank which makes themeasiertofindreferences.Afterthat,theregoestheexamproblemsetwhichcouldbe 
used by students immediately. When students are done answering the exam, teachers are spared from administrative tasks, because they can directly see the compiled scores and problem-item analysis. The administrative tasks are done automatically.

\section{Key Factors That Trigger Teacher and School Stakeholders to Adopt CBT}

\section{School Stakeholders}

Stakeholders are Vice Principal of Curriculum in SMANBARA and Principal of SMPN 1. Both of them realized that nowadays, all teachers must have a high proficiency in technology. According to Syukur (2014), teachers must adapt and adopt ICT in their lives because of 1) Demands from school or government; 2) Awareness to create the teachinglearning system more interesting, effective, and efficient. That is why both of them continuously encourage their teachers to use technology during learning at teaching and very open to new technologies.

According to the interview with Vice Principal of SMANBARA, CBT helped the school a lot. Before they use CBT, they had to go in the dawn to bring problems for the national exam. Using CBT in their daily also help in reducing paper use. Papers were used to out in November, so they had to copy the problems using newsprint paper. The Vice Principal also said that CBT has direct-scoring feature which helps.

While the principal of SMPN 1 told us that CBT required huge investment at only the beginning. Nevertheless, it reduces the exam cost, because one exam costs IDR 10 million. It also reduces the resource needed for being supervisors during the exam, from 30 people to only six people. The principal thought that CBT presence would help teachers by not checking the exam papers because the students usually have bad handwriting which complicates teachers during checking.

\section{Teacher Adoption}

The adoption of technology in the classroom is highly correlated with teacher perceptions in digital technology (Domingo and Garganté, 2015). One of key aspect in building better teachers' perceptions to the technology is to give them proper training and simulation before giving them the technology, so they will percieved the technology will ease their working load (Goktaset al., 2009). For this reason, when training is held to the teacher, we divided our training into two groups.

The first group is for the teacher in general, we only trained them to the most basicand easiest way to use our CBT application, this process intended to make teacherand other 
than teacher perceive that using our CBT application is very easy. The second group consists of school admin and some teacher with exceptionally high technology-literacy, this group will be trained to use our full features of our CBT. The second group is planned to guide the first group in using CBT in their daily activity. This method can be considered as successful, and evaluation results prove it with the questionnaire, most teachers consider that the CBT system can ease their workloads in making the question (Figure 5) and evaluating test results (Figure6).

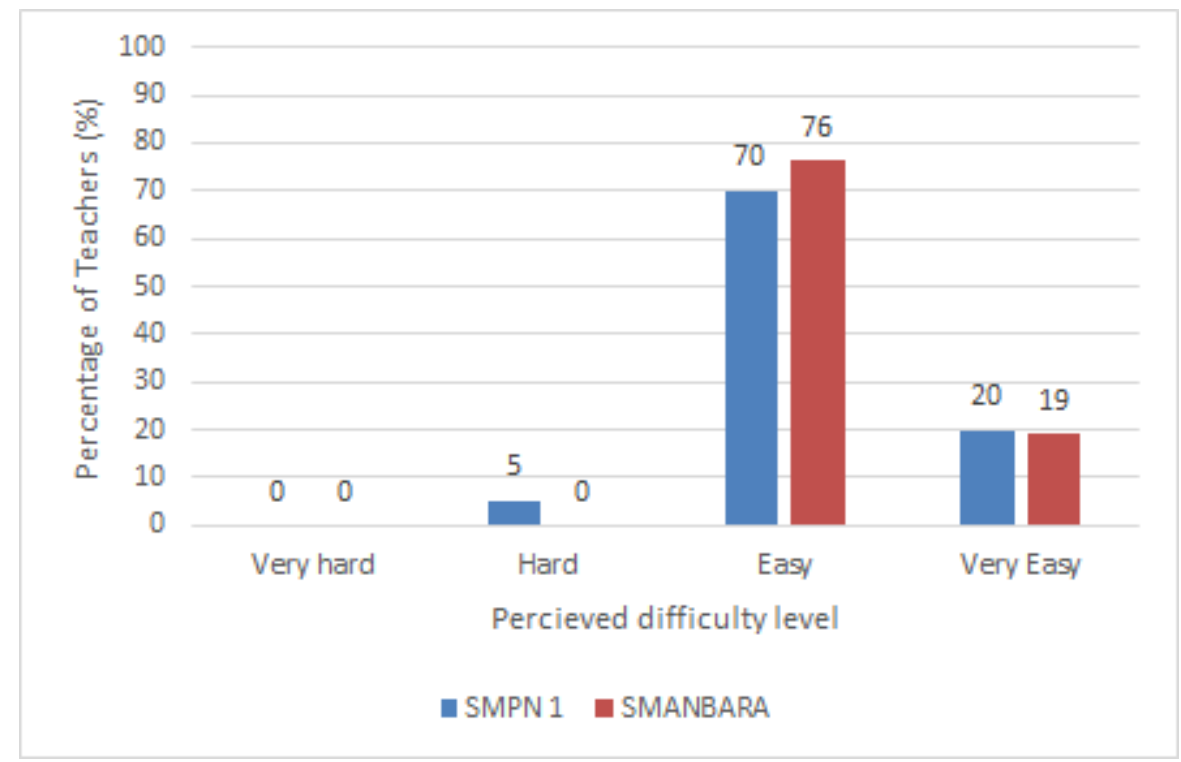

Figure 6. Perceived difficulty level in Creating

Exam Package

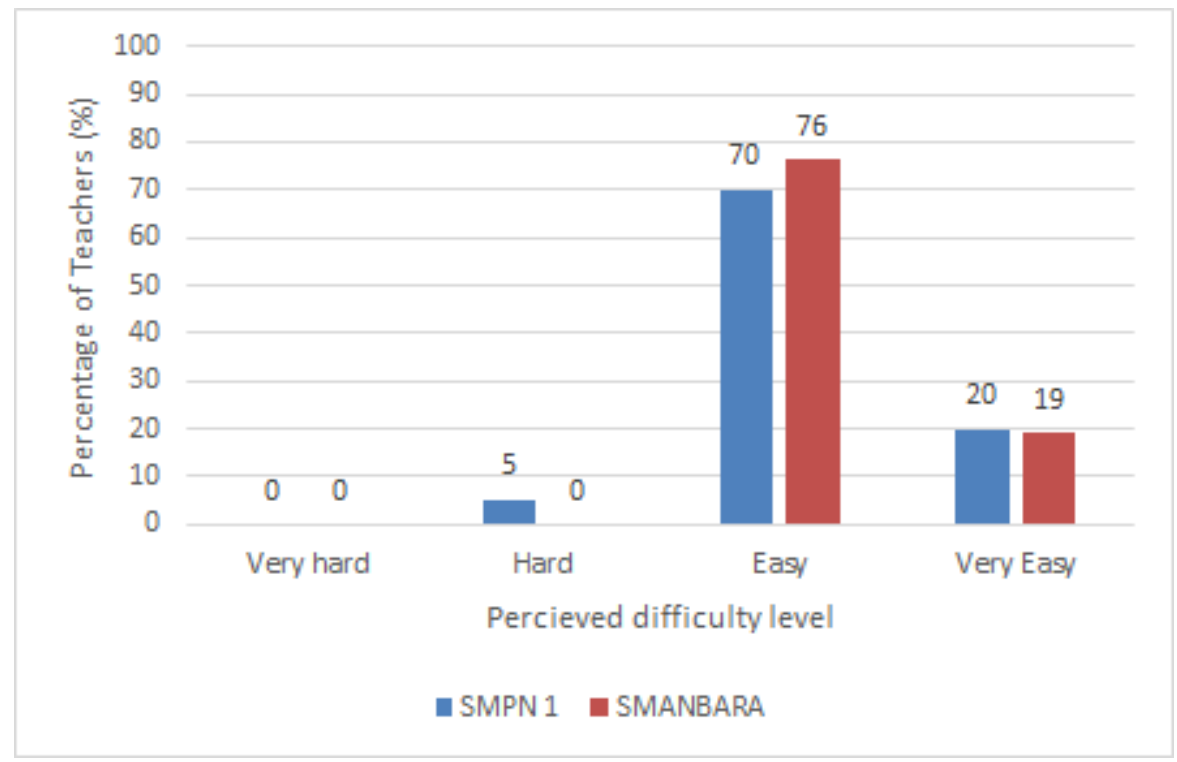

Figure 7. Perceived difficulty level in Analyzing Exam Result 
Based on the results of this research, it is known that the teachers in SMANBARA consider that CBT system is more easy to use than teachers in SMPN 1, this might be due to differences in their demographic groups based on age in both schools. SMANBARA has the much younger composition of teachers. The younger teachers are predicted to be more receptive to new things than older teachers. This shows at the Figure 5 and Figure 6 above at how their comprehension in understanding "Creating Exam Package" and "Analyzing Exam Result". Teachers from SMANBARA show higher percentage on 'easy' and 'very easy' level. The prediction was also supported by the saying of SMPN 1 principal who said that senior teachers are harder to be exposed to technology. This can conclude that most of theteachers thought that both of the features are easy touse.

\section{Later Adoption}

Adoption process through comprehensive training, workshop, and simulation resulted in later adoption. Later adoption could be seen from their willingness to use our CBT on their daily activities. This could be seen in Figure 8, where the respondents could choose more than one answers.

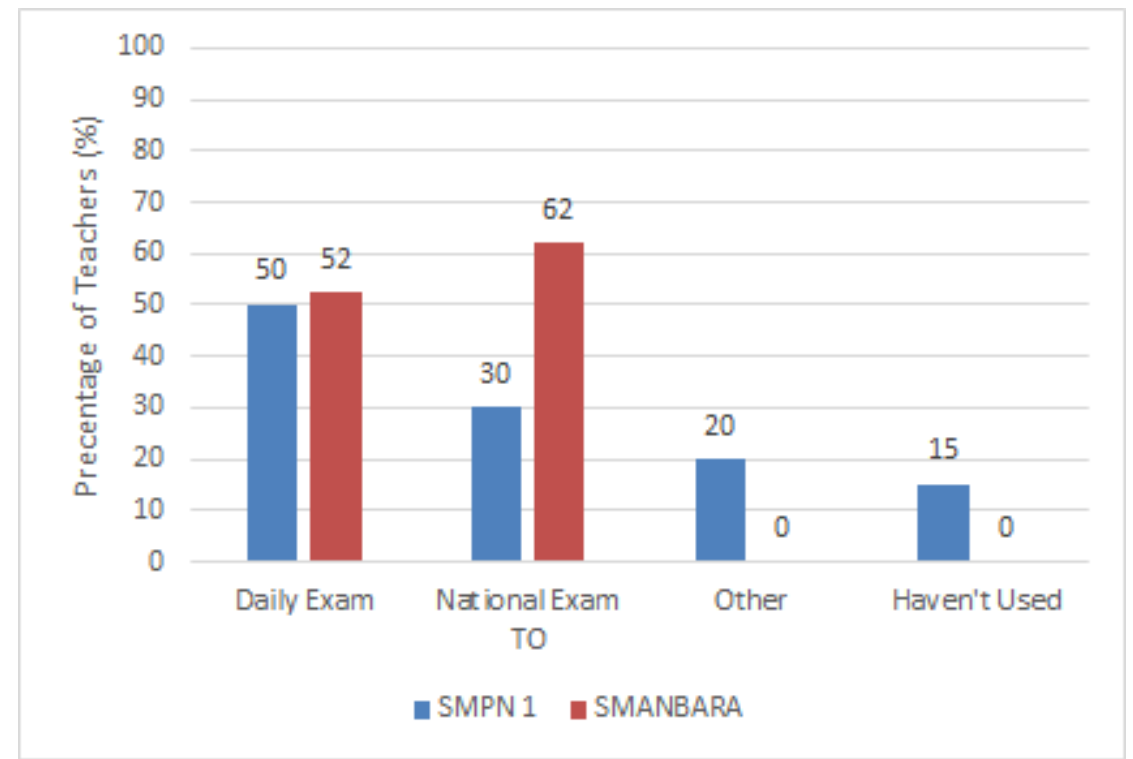

Figure 8. The CBT Usage in Teacher's Activities

Based on Figure 8 above, we can conclude that all teachers in SMANBARA had used the CBT while $15 \%$ of SMPN 1 teachers had not used it afterward. We assumed that SMPN 1 teachers who did not use CBT were because of the lack of technology-literate, supported by their age range and its principal's statement who said that senior teachers are harder to be encouraged to use technology in the learning process. Around $50 \%$ of the teachers use the CBT in daily exams. In SMANBARA, 62\% of the teachers use it for National Exam Tryout. Meanwhile, $30 \%$ of SMPN 1 teacher use it for National Exam Tryout, and $20 \%$ of them use it for other things, this can quiz. 


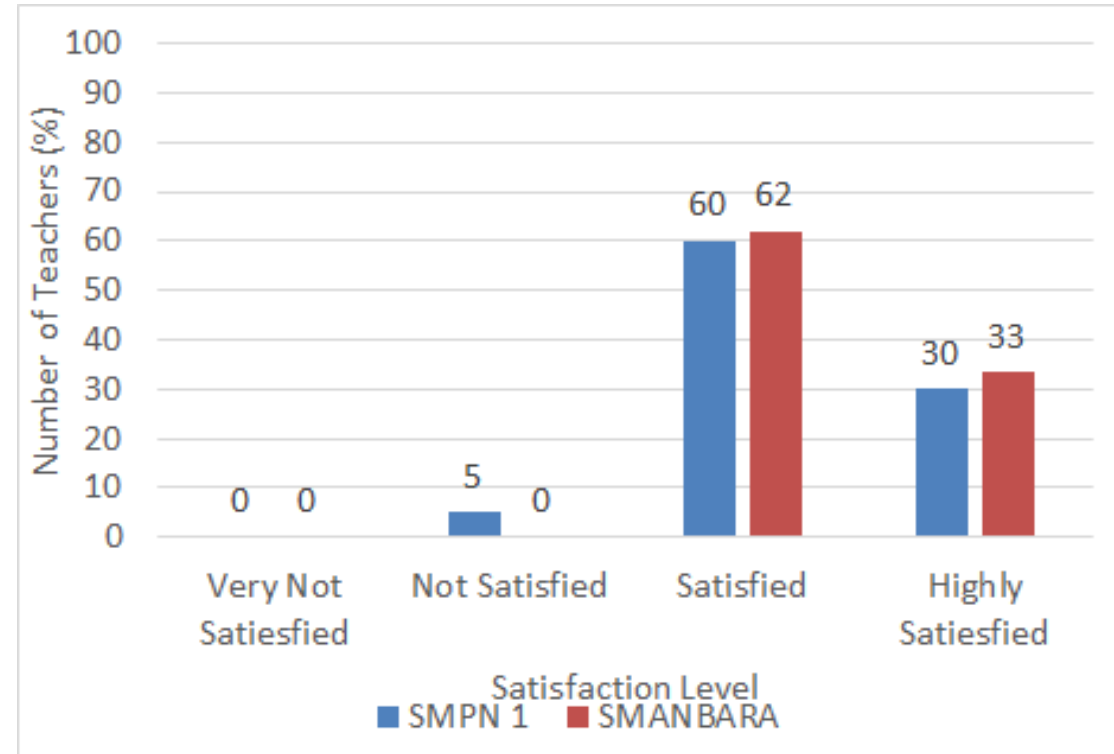

Figure 9. Teacher Satisfaction Level in Using Our CBT in Creating Exam Package and Analyzing Exam Result

After they used the CBT in their daily activities, we also counted their satisfaction level of the use. Both schools showed a high level of satisfaction. Around $60 \%$ of the teachers from both schools are feeling satisfied with the CBT, and around $30 \%$ of them are feeling highly satisfied. About $5 \%$ of the teachers from SMPN 1 are feeling not satisfied. We predicted that this was because of the expected features that were not present.

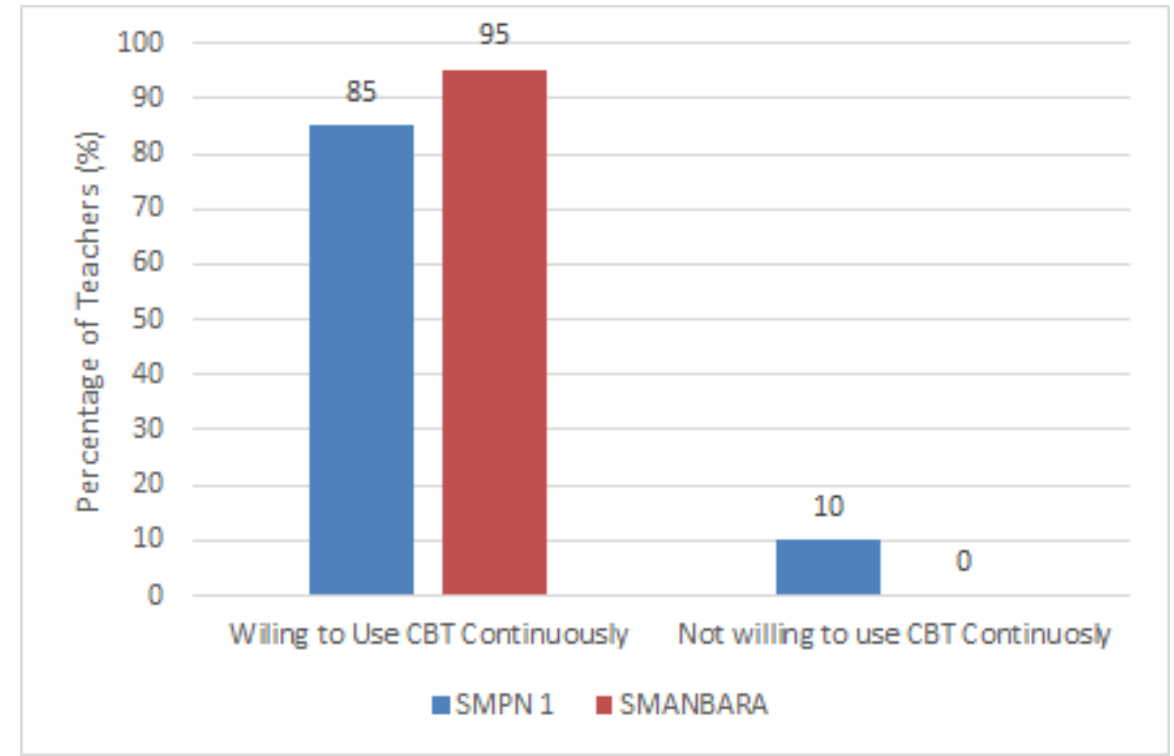

Figure 10. Willingness to Use CBT System Continuously 
From the two figures above (Figure 8 and Figure 9), from their use of CBT in their daily lives and level of satisfaction, we can see the willingness of the teachers to use CBT continuously. About $85 \%$ of SMPN 1 teachers are willing to use it again, while $10 \%$ are not willing to use. By $95 \%$ of SMANBARA teachers are willing to use it again in the future.

Both schools show no significant difference in the adoption process. If we relate to teachers' demography, we can see that our CBT are easy to use regardless of the user's age and technology-literacy. That is expected to be an essential point to keep encouraging teachers nowadays to be adapted to use technology in the learning process in the future.

\section{Conclusion}

Conclusions of the research are CBT use is more effective than PBT use because it can save paper and money, reducing resource needed during the exam, lessen the time that teachers need to make problem sets, and simplifying the scoring process. Thus, stakeholders of both schools are keen to adopt CBT system their schools, aided by their characters visions that are willing to encourage the teachers to be more technology-literate. Particular features that favorable are upload problems in images simultaneously, direct-scoring, and automatic question-item analysis. Our research from observations until evaluations showed that the teacher would be more adapted to technology through some gradual steps. Comprehensive steps started from training to the workshop, then simulation that is proven to be vital in teachers' adoption process.

\section{References}

Al-QahtaniAwadh A.Y. and S.E. Higgins.(2013). Effects of traditional, blended and elearning on students' achievement in higher education. Retrieved November 2018 from https://onlinelibrary.wiley.com/doi/abs/10.1111/j.1365-2729.2012.00490.x

BoevéAnja J., Rob R. Meijer, Casper J. Albers, YtaBeetsma, Roel J. Bosker. (2018). Introducing Computer-Based Testing in High Stakes Exams in Higher Education: Results of a Field Experiment. Retrieved November 2018 from https://www.ncbi.nlm.nih.gov/pubmed/26641632

Domingo M Gómez and GargantéAntoniBadia . (2015). Exploring the use of educational technology in primary education: Teachers' perception of mobile technology learning impacts and applications' use in the classroom. Retrieved November 2018 from https://www.sciencedirect.com/science/article/pii/S0747563215302387

Furió D. , M.-C. Juan, I. Seguí, and R. Vivó. (2014). Mobile learning vs. traditional classroom lessons: a comparative study. Retrieved November 2018 from https://onlinelibrary.wiley.com/doi/abs/10.1111/jcal.12071 
GoktasYuksel, SonerYildirim, and ZahideYildirim.(2009). Main Barriers and Possible Enablers of ICTs Integration into Pre-service Teacher Education Programs. Retrieved November 2018 from https://www.j-ets.net/ets/journals/12 1/15.pdf

Syukur, Imam B. (2014). Teacher professionalism in implementing information and communication technology in Nganjuk District. Retrieved November 2018 from https://www.researchgate.net/publication/323630745 Profesionalisme Guru dalam Me ngimplementasikan Teknologi Informasi dan Komunikasi di Kabupaten Nganjuk

Retnawati Hera, SamsulHadi, Ariadie C. Nugraha. (2017). Implementing The ComputerBased National Examination In Indonesian Schools: The challenges and strategies. Retrieved November 2018 from http://oaii.net/articles/2017/457-1513710818.pdf

Tondeur J, JohanvanBraak, FazilatSiddiq, and Ronny Scherer. (2016). Time for a new approach to prepare future teachers for educational technology use: Its meaning and measurement. Retrieved November 2018 https://www.sciencedirect.com/science/article/pii/S0360131515300816

Wang Shudong, Hong Jiao, Michael J. Young, Thomas Brooks, John Olson.(2018). Comparability of Computer-Based and Paper-and-Pencil Testing in K-12 Reading Assessments. Retrieved November 2018 https://journals.sagepub.com/doi/10.1177/0013164407305592

\section{Website}

Kemendikbud.(2018). About. Retrieved November 2018 from https://unbk.kemdikbud.go.id/tentang\#content 